\title{
Content of Antenatal Education and Modalities of Delivery among Nurses in Oyo State, Nigeria
}

\author{
Margaret O. Akinwaare, Arinade O. Oyebode, Victoria B. Brown, \\ Abiodun A. Ogunniran, and Khadijat K. Adeleye
}

\section{ABSTRACT}

Background: There is no structured content and modalities for the delivery of antenatal education in Nigerian healthcare institutions. Hence, the lack of knowledge on salient issues that are pivotal to survival of mothers and their babies among childbearing women. This study assessed the contents and mode of delivery of antenatal education from the perspective of care providers.

Methods: A descriptive cross-sectional study design was adopted using structured questionnaire developed by the researchers for data collection. One hundred and ten nurses were recruited across various healthcare institutions in Oyo state, Nigeria to participate in the study.

Results: The mean age of the nurses is 39.7 with standard deviation of 10.1. About half $(\mathbf{4 3 . 6 \%})$ of them have first degree in Nursing, while one-third $(31.8 \%)$ are at the lower cadre of Nursing (Nursing officer II). The most common five topics taught by the nurses as reported are; hygiene $(98.2 \%)$, diet $(84.6 \%)$, immunization $(31.8 \%)$, birth preparedness $(31.8 \%)$, and breastfeeding $(28.2 \%)$. The most common mode of delivery is face-to-face teaching $(\mathbf{9 8 . 2 \%})$ while e-teaching is least employed (20.9\%). Pictures $(\mathbf{8 7 . 3 \%})$ and posters $\mathbf{( 7 9 . 1 \% )}$ are the most common materials used for teaching while majority $(\mathbf{7 2 . 7 \%})$ provide fliers as teaching materials to their clients. Majority $(\mathbf{9 8 . 2 \%})$ of the nurses' state that they provide antenatal education to serve as learning forum for their clients, however, very few $(\mathbf{1 7 . 3 \%})$ stated that they provide antenatal education to keep their clients busy while waiting for doctor's consultation.

Conclusion: There is no structured content for antenatal education being offered to pregnant women during antenatal clinic. However, every pregnant woman attending antenatal clinic will benefit from balanced information that will enhance positive pregnancy outcome from her care provider. Hence the need for structured content and modalities of delivery of antenatal education in Nigeria.

Keywords: Antenatal education, Nigeria, Nurses, Pregnancy.
Submitted : September 30, 2020

Published : April 27, 2021

ISSN: $2593-8339$

DOI: $10.24018 /$ ejmed.2021.3.2.502

Margaret O. Akinwaare *

RN, RM, RPHN, MSc

Lecturer (Maternal and Child Health Nursing)

Department of Nursing, Faculty of Clinical Sciences, College of Medicine, University of Ibadan, Ibadan, Nigeria.

(e-mail: margaretakinwaare ${ }^{@}$ gmail.com)

Arinade O. Oyebode

RN, RM, MSc

Deputy Director Nursing Services

Oyo State Ministry of Health, Agodi Secretariat, Ibadan, Nigeria.

Victoria B. Brown

$\mathrm{RN}, \mathrm{PhD}$, Tutor

School of Nursing, University College

Hospital, Ibadan, Nigeria.

Abiodun A. Ogunniran

RN, RM, MSc

Principal, School of Midwifery, Oyo State

College of Nursing and Midwifery,

Eleyele, Ibadan, Nigeria.

Khadijat K. Adeleye

RN, RM, MSc, Assistant lecturer

Lagos State University, College of

Medicine, Ikeja, Lagos, Nigeria.

*Corresponding Author

\section{INTRODUCTION}

Antenatal care is an important predictor of safe delivery, provision of health information and services that can improve the health of women and infants [1]. Sub-Saharan African countries accounts for roughly two-thirds (196 000) of global maternal mortality, which Nigeria is one of them [2]. Nigeria is facing a public health crisis concerning maternal health outcomes, and it is presently the second largest contributor to global maternal deaths, having a maternal mortality ratio of 917 per 100,000 live births [3]. Basic antenatal care approach is one of the priority interventions in achieving sustainable development goals targeted at reduction in maternal deaths to less than 70 per 100,000 live births by 2030 [4]. Majority of the contributory factors of maternal mortality could be avoided if preventive measures were taken and adequate care available [5]. Nigeria still experiences a high burden of unsafe motherhood, in which bleeding accounts for the majority [3], which could be an indication of the missed opportunities during health talks at antenatal visits [6].

Nurses during antenatal care could provide pregnant women with valuable information and advices that promote health and wellbeing in the ante natal, post-natal and in parenting period. This education is often available in the form of individual sessions or as a group educational programme. During Ante natal classes, educational programme provided should include care during pregnancy, danger signs during pregnancy, labor and after birth, the labor process and the postnatal care for the mother and the baby [7]. A family-oriented antenatal group educational program has potential to increase knowledge, birth preparedness in rural Tanzania [8]. Information, education, and counselling plays a vital role in improving birth preparedness and complication readiness, and hence prevention of maternal death [6]. Reference [9] reported that Instructional package during ante natal is of upmost benefit in helping pregnant women to acquire knowledge regarding 
good health seeking behavior. In addition, it was documented that in Nigeria, the health education package received during ANC visits by pregnant women were of optimal satisfaction [10]. Use of self-instructional module by Nurses was useful to improve the health seeking behavior of primigravida mothers regarding antenatal care [11]. Antenatal educational guidelines were observed to have a significant benefit in improving mother's knowledge of pregnancy that could have a positive impact on their mother's and child's health [12].

Antenatal education is dependent on culture, and it should be planned in such a way that its content and methodology do not increase fear. It was observed that in low -middle income countries, a group ante natal education helps pregnant women to build skills and confidence, share experiences and resources, and socialize with one another [13]. Reference [14] observed that education and information provided during ante natal care would have positive impact on willingness to access and health-seeking behaviors towards ante natal care service. In Ireland it was observed that pregnant women often had limited educational resources available to them [15]. Ante natal education which focuses on exclusive breast feeding, is a measure of promoting positive breast-feeding practice [16]. The maternal nutrition education given to pregnant women during antenatal care was inadequate in scope and depth [17]. During ante natal classes, provision of nutritional information and support was noticed to be inaccurate and dismissiveness of scientific advice [18]. In Malawi, it was proposed that content of ante natal education should be split into two areas, which should be birth and emergency preparation during maternity period, and, information disseminated during ante natal classes for couples should be prioritized [19]. Pregnant women stated some important domain of information needed during ante natal education from the nurses includes complications of pregnancy, medicine intake, fetal care, the management of minor complications and smoking and its effect [20]. In Nigeria, [6] observed that some contents of information delivered during ante natal classes is poor, such as key elements of birth preparedness and complication readiness (BAPCR). Also, in Enugu state, Nigeria, maternal health education increased health knowledge of pregnant mothers [21].

Also, good rapport and interactive learning were the two most quoted important characteristics of antenatal education classes at health care facilities of Brunei Darul Salam [22]. Antenatal education provided through verbal information was identified as the least interesting to the women [22]. In addition, [23] reported that use of mobile phone has a modality to disseminate information to pregnant women has empowered them and encourage the ability to voice out their opinions and expose unlawful practices. Contents, channels, and formats of antenatal educational should be adapted according to the preferences of the target population [24]. In addition, covering a broader range of educational content is essential during ante natal care [25]. The use of informal virtual classes, along with the peer interaction on the social media, had a significant improvement on the pregnancy related information for first-time mothers [23]. Television and Internet were also identified as preferred sources of information [6]. Moreover, [26] reported that exploring the value of ante natal classes among pregnant women has the potential to result to improve attendance, reduced dropout rates and overall greater satisfaction. Reference [8] documented that antenatal education can be provided in a rural community using drama, reading picture

Both content and methods of antenatal education have changed over time without evidence of effects on relevant outcomes. Antenatal education programmes in developing countries are usually of a less formal nature. Women in such low-middle income countries receive information about childbirth and parenting from informal sources such as family elders or via medical staff in antenatal clinics. However, there is no adequate documentation on content and methodology of ante natal education offered during the antenatal care, and whether the ante natal education guidelines have been implemented as stipulated. Therefore, this study set out to provide first-hand information on content of antenatal education and modalities of delivery from the nurses' perspectives. It is intended that the findings of this study will serve as an evidence-based data for proper implementation of antenatal education for quality antenatal care.

\section{Methods AND Materials}

\section{A. Study Design}

This study adopted a descriptive cross-sectional design and utilized quantitative approach.

\section{B. Study Setting}

The study was conducted among nurses/midwives in Oyo state, one of the six states in the South-Western Nigeria. Nurses/midwives in the state are scattered across the private hospitals and public healthcare facilities which includes: the primary healthcare centers, secondary health institutions and tertiary health institutions.

\section{Study Participants/Sampling Technique}

Purposive sampling technique was used to select one hundred and ten nurses/midwives across the state.

\section{Data Collection}

A structured self-administered questionnaire was used for data collection. The instrument was developed by the researchers through a thorough literature search in relation to the objectives of the study. Respondents were met face to face and questionnaires were administered. All questionnaires administered were retrieved back and included in data analysis given a $100 \%$ response rate. Descriptive variables were presented on frequency tables, Chi-sq was used to test association between variables while the significance was set at $<0.05$.

\section{RESULTS}

\section{A. Socio-demographic Characteristics of Respondents}

On the average, the estimated age of the participants was about 40 years with a standard deviation of 10 years. Most of the nurses and midwives (44\%) had attained a university first degree, the distribution of the nurses and midwives by their cadre showed that one-fifth of them were nursing officer (NO I), while one-third (32\%) were nursing officer (NO II). 
TABLE I: SOCIO-DEMOGRAPHIC CHARACTERISTICS OF PARTICIPANTS

\begin{tabular}{|c|c|c|}
\hline & $\begin{array}{c}\text { Frequency } \\
(\mathrm{n}=110)\end{array}$ & Percentage \\
\hline \multicolumn{3}{|l|}{ Age $39.7 \pm 10.1$} \\
\hline 20-29 years & 23 & 20.9 \\
\hline $30-39$ years & 34 & 30.9 \\
\hline $40-49$ years & 28 & 25.5 \\
\hline$\geq 50$ years & 25 & 22.7 \\
\hline \multicolumn{3}{|l|}{ Marital Status } \\
\hline Single & 21 & 19.1 \\
\hline Married & 83 & 75.5 \\
\hline Widow/Separated & 6 & 5.6 \\
\hline \multicolumn{3}{|l|}{ Highest Educational Level } \\
\hline Postgraduate & 4 & 3.6 \\
\hline University first degree & 48 & 43.6 \\
\hline $\mathrm{RN}$ & 9 & 8.2 \\
\hline $\mathrm{RM}$ & 1 & 0.9 \\
\hline $\mathrm{RN}+\mathrm{RM}$ & 27 & 24.5 \\
\hline $\mathrm{RN}+$ any other post-basic & 21 & 19.1 \\
\hline \multicolumn{3}{|l|}{ Religion } \\
\hline Christianity & 97 & 88.2 \\
\hline Islam & 10 & 9.1 \\
\hline No record & 3 & 2.7 \\
\hline \multicolumn{3}{|l|}{ Ethnicity } \\
\hline Yoruba & 93 & 84.5 \\
\hline Igbo & 13 & 11.8 \\
\hline Hausa & 1 & 0.9 \\
\hline Others & 3 & 2.7 \\
\hline \multicolumn{3}{|l|}{ Cadre } \\
\hline NO I & 22 & 20.0 \\
\hline NO II & 35 & 31.8 \\
\hline SNO & 9 & 8.2 \\
\hline PNO & 6 & 5.5 \\
\hline ACNO & 5 & 4.5 \\
\hline $\mathrm{CNO}$ & 26 & 23.6 \\
\hline AND & 6 & 5.5 \\
\hline DDN & 1 & 0.9 \\
\hline
\end{tabular}

\section{B. Topics Taught during Health Education}

Information gathered from the nurses and midwives as regards the health education topics they teach the mothers who attend the health facility revealed that, all the participants confirmed some topics were statutorily taught (100\%)- education on diet. More than $95 \%$ to $99 \%$ of the nurses and midwives affirmed that education on matters such as hygiene, immunization, breastfeeding, rest and sleep, exercises and relaxation, medications and infection were given to the mothers who visited their respective facilities. $90 \%$ to $94 \%$ of the nurses and midwives acknowledged their health education topics taught to clients included education on family planning, umbilical cord care, essential newborn care, sexual counselling, danger signs during pregnancy, follow-up, danger signs during postpartum period, and danger signs during labour. Over $70 \%$ to $89 \%$ acknowledged they had educated their clients on topics such as physiological changes during pregnancy, weight gain, daily activities, birth preparedness and complication readiness, occupational and environmental hazards, smoking, minor discomforts, as well as bladder and bowel. More than half remarked topics such as education on teeth, fresh air and sunshine, travel, and irradiation as the least taught topics in their various facilities. The five commonest health education topics remarked by the nurses and midwives were: Hygiene (98\%), Diet (85\%), Immunization (32\%), Birth preparedness (32\%), and Breastfeeding (28\%).
TABLE II: ANTENATAL EDUCATION TOPICS TAUGHT BY PARTICIPANTS

\begin{tabular}{|c|c|c|}
\hline Variables & Yes & No \\
\hline Diet & $110(100 \%)$ & - \\
\hline Hygiene & $109(99.1 \%)$ & $1(0.9 \%)$ \\
\hline Immunization & $108(98.2 \%)$ & $2(1.8 \%)$ \\
\hline Breastfeeding & $108(98.2 \%)$ & $2(1.8 \%)$ \\
\hline Rest and sleep & $107(97.3 \%)$ & $3(2.7 \%)$ \\
\hline Exercises and relaxation & $107(97.3 \%)$ & $3(2.7 \%)$ \\
\hline Medications & $105(95.5 \%)$ & $5(4.5 \%)$ \\
\hline Infection & $104(94.5 \%)$ & $6(5.5 \%)$ \\
\hline Family planning & $103(93.6 \%)$ & $7(6.4 \%)$ \\
\hline Umbilical cord care & $102(92.7 \%)$ & $8(7.3 \%)$ \\
\hline Essential newborn care & $102(92.7 \%)$ & $8(7.3 \%)$ \\
\hline Sexual counselling & $101(91.8 \%)$ & $9(8.2 \%)$ \\
\hline Danger signs during pregnancy & $101(91.8 \%)$ & $9(8.2 \%)$ \\
\hline Follow up & $100(90.9 \%)$ & $10(9.1 \%)$ \\
\hline $\begin{array}{l}\text { Danger signs during postpartum } \\
\text { period }\end{array}$ & $100(90.9 \%)$ & $10(9.1 \%)$ \\
\hline Danger signs during labour & $99(90.0 \%)$ & $11(10.0 \%)$ \\
\hline $\begin{array}{l}\text { Physiological changes during } \\
\text { pregnancy }\end{array}$ & $98(89.1 \%)$ & $12(10.9 \%)$ \\
\hline Weight gain & $98(89.1 \%)$ & $12(10.9 \%)$ \\
\hline Daily activities & $97(88.2 \%)$ & $13(11.8 \%)$ \\
\hline $\begin{array}{l}\text { Birth preparedness and } \\
\text { complication readiness }\end{array}$ & $96(87.3 \%)$ & $14(12.7 \%)$ \\
\hline $\begin{array}{l}\text { Occupational and environmental } \\
\text { hazards }\end{array}$ & $95(86.4 \%)$ & $15(13.6 \%)$ \\
\hline Smoking & $92(83.6 \%)$ & $18(16.4 \%)$ \\
\hline Minor discomforts & $90(81.8 \%)$ & $20(18.2 \%)$ \\
\hline Bladder and bowel & $87(79.1 \%)$ & $23(20.9 \%)$ \\
\hline Teeth & $76(69.1 \%)$ & $34(30.9 \%)$ \\
\hline Fresh air and sunshine & $65(59.1 \%)$ & $45(40.9 \%)$ \\
\hline Travel & $63(57.3 \%)$ & $47(42.7 \%)$ \\
\hline Irradiation & $56(50.9 \%)$ & $54(49.1 \%)$ \\
\hline
\end{tabular}

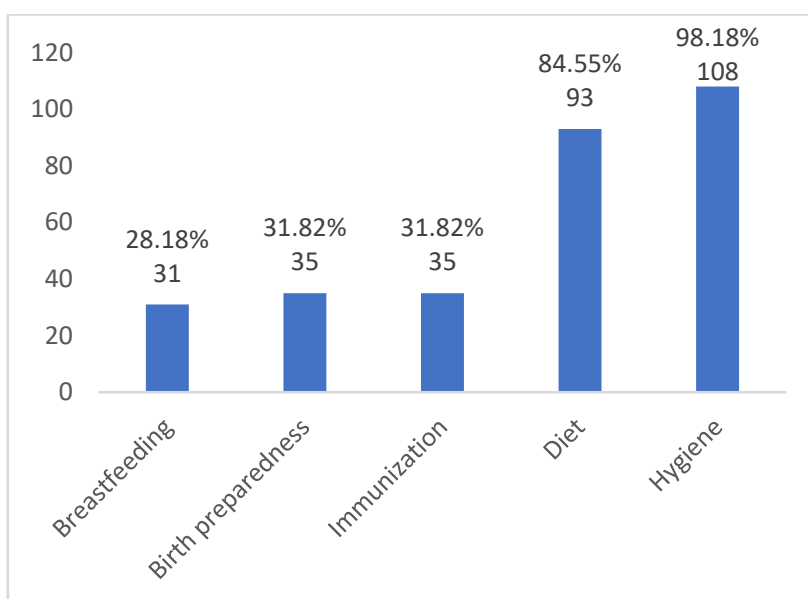

Fig. 1. Five commonest antenatal education topics offered by the participants.

\section{Teaching Methods and Materials Used during Antenatal Education by Nurses}

From a list of four different methods adopted by the nurses and midwives, the most of them remarked they used the teaching methods while educating the clients (98\%), a majority also acknowledged using question and answer techniques during the education of clients, less than half reported they adopted learning methods for their clients, while just $21 \%$ reported used of electronic teaching techniques.

The nurses and midwives also emphasized on materials they used during education of their clients. Materials such as pictures were most commonly used by the health educators $(87 \%)$; more the three-quarter hinted on the use of posters (79\%); less than half of the educators mentioned the use of projector and audio tape, $35 \%$ and $22 \%$ respectively. 
In addition to the methods, they adopt in educating their clients and materials used, the nurses and midwives affirmed they gave out some teaching materials to their clients to enhance their educational practices; these include - fliers $(73 \%)$, booklets $(50 \%)$ and white materials $(40 \%)$.

TABLE III: METHODS AND MATERIALS OF ANTENATAL EDUCATION USED

\begin{tabular}{lcc}
\multicolumn{3}{c}{ BY THE PARTICIPANTS } \\
\hline Yethod Used & No \\
\hline Teaching method & $108(98.2 \%)$ & $2(1.8 \%)$ \\
Question \& answer & $90(81.8 \%)$ & $20(18.2 \%)$ \\
methods & $53(48.2 \%)$ & $57(51.8 \%)$ \\
Lecturing method & $23(20.9 \%)$ & $87(79.1 \%)$ \\
E-teaching & & \\
Materials Used & $96(87.3 \%)$ & $14(12.7 \%)$ \\
Pictures & $87(79.1 \%)$ & $23(20.9 \%)$ \\
Posters & $39(35.5 \%)$ & $71(64.5 \%)$ \\
Projector & $24(21.8 \%)$ & $86(78.2 \%)$ \\
Audio tape & & \\
Teaching Materials given & & \\
to Clients & $80(72.7 \%)$ & $30(27.3 \%)$ \\
Fliers & $55(50 \%)$ & $55(50 \%)$ \\
Booklets & $44 \quad 40 \%)$ & $66(0 \%)$ \\
White materials & &
\end{tabular}

\section{Purpose of Antenatal Education Provided by Nurses}

The purpose for which the nurses undertake their various health education topics was also revealed from the study; it was found that almost all, 98\%, indicated they had discharged their health educational duties to serve as a learning forum for their clients; approximately three-quarter $(74.5 \%)$ reported they engaged in educating their clients for purpose of statutory clinic routine; almost half of the educators, $49 \%$, made known that they educated the clients to showcase themselves as health educators; a very few indicated that they engage in educating their clients just to keep them busy while waiting for doctor's consultation, $17 \%$.
TABLE IV: PARTICIPANTS' PURPOSE OF PROVIDING ANTENATAL

\begin{tabular}{|c|c|c|}
\hline \multicolumn{3}{|c|}{ EDUCATION } \\
\hline & Yes & No \\
\hline $\begin{array}{l}\text { To serve as a learning forum for } \\
\text { clients }\end{array}$ & $108(98.2 \%)$ & $2(1.8 \%)$ \\
\hline As a clinic routine & $82(74.5 \%)$ & $28(25.5 \%)$ \\
\hline $\begin{array}{l}\text { To showcase nurses as health } \\
\text { educators }\end{array}$ & $54(49.1 \%)$ & $56(50.9 \%)$ \\
\hline $\begin{array}{l}\text { To keep clients busy while waiting } \\
\text { for doctor's consultation }\end{array}$ & $19(17.3 \%)$ & $91(82.7 \%)$ \\
\hline
\end{tabular}

\section{E. Association between Nurses' Educational Qualification and Topic Taught during Antenatal Education}

Test of association was carried out between the educational qualification of the midwives and the topic they taught during health education. Using a significance level of $5 \%$, it was found that the participants' level of education was not significantly associated with none of the topics taught by the health educators, as the p-values obtained from the test were generally greater than $5 \%$, thus leading to acceptance of the null hypothesis.

Notable from the result was that, nurses and midwives with university degrees (first degree and postgraduate) generally engaged more in teaching of certain topics such as - physiological changes during pregnancy, weight gain, fresh air and sunshine, rest and sleep, bladder and bowel, sexual counselling, medications, infection, follow-up, minor discomforts, birth preparedness and complication readiness, danger signs during pregnancy, danger signs during labour, danger signs during postpartum period, breastfeeding, family planning, umbilical cord care, and essential newborn care. Conversely, nurses and midwives with other qualifications (RN, RM, RN + RM, RM + other post-basic) generally engaged more in educating clients on specific topics, like daily activities, exercises and relaxation, teeth, smoking, irradiation, occupational and environmental hazards, and travel.

TABLE V: ASSOCIATION BETWEEN NURSES’ EDUCATIONAL QUALIFICATION AND TOPIC TAUGHT DURING ANTENATAL EDUCATION

\begin{tabular}{|c|c|c|c|c|}
\hline & & Yes & No & $\chi^{2}$ (p-value) \\
\hline \multirow{2}{*}{$\begin{array}{l}\text { Physiological changes during } \\
\text { pregnancy }\end{array}$} & University Degree (UG \& PG) & $48(92.3 \%)$ & $4(7.7 \%)$ & 1.05 \\
\hline & RN \& RM & $50(86.2 \%)$ & $8(13.8 \%)$ & $(0.306)$ \\
\hline \multirow{2}{*}{ Weight gain } & University Degree (UG \& PG) & $48(92.3 \%)$ & $4(7.7 \%)$ & 1.05 \\
\hline & $\mathrm{RN} \& \mathrm{RM}$ & $50(86.2 \%)$ & $8(13.8 \%)$ & $(0.306)$ \\
\hline \multirow{2}{*}{ Fresh air and sunshine } & University Degree (UG \& PG) & $32(61.5 \%)$ & $20(38.5 \%)$ & 0.24 \\
\hline & RN \& RM & $33(56.9 \%)$ & $25(43.1 \%)$ & $(0.621)$ \\
\hline \multirow{2}{*}{ Rest and sleep } & University Degree (UG \& PG) & $51(98.1 \%)$ & $1(1.9 \%)$ & 0.24 \\
\hline & $\mathrm{RN} \& \mathrm{RM}$ & $56(96.6 \%)$ & $2(3.4 \%)$ & $(0.624)$ \\
\hline \multirow{2}{*}{ Daily activities } & University Degree (UG \& PG) & $45(86.5 \%)$ & $7(13.5 \%)$ & 0.26 \\
\hline & RN \& RM & $52(89.7 \%)$ & $6(10.3 \%)$ & $(0.613)$ \\
\hline \multirow{2}{*}{ Exercises and relaxation } & University Degree (UG \& PG) & $52(100 \%)$ & 0 & 2.77 \\
\hline & $\mathrm{RN} \& \mathrm{RM}$ & $55(94.8 \%)$ & $3(5.2 \%)$ & $\left(0.245^{F i}\right)$ \\
\hline \multirow{2}{*}{ Teeth } & University Degree (UG \& PG) & $35(67.3 \%)$ & $17(32.7 \%)$ & 0.15 \\
\hline & RN \& RM & $41(70.7 \%)$ & $17(29.3 \%)$ & $(0.702)$ \\
\hline \multirow{2}{*}{ Bladder and bowel } & University Degree (UG \& PG) & $45(86.5 \%)$ & $7(13.5 \%)$ & 3.31 \\
\hline & $\mathrm{RN} \& \mathrm{RM}$ & $42(72.4 \%)$ & $16(27.6 \%)$ & $(0.069)$ \\
\hline \multirow{2}{*}{ Sexual counselling } & University Degree (UG \& PG) & $49(94.2 \%)$ & $3(5.8 \%)$ & 0.76 \\
\hline & RN \& RM & $52(89.7 \%)$ & $6(10.3 \%)$ & $(0.382)$ \\
\hline \multirow{2}{*}{ Smoking } & University Degree (UG \& PG) & $43(82.7 \%)$ & $9(17.3 \%)$ & 0.06 \\
\hline & $\mathrm{RN} \& \mathrm{RM}$ & $49(84.5 \%)$ & $9(15.5 \%)$ & $(0.800)$ \\
\hline \multirow{2}{*}{ Medications } & University Degree (UG \& PG) & $51(98.1 \%)$ & $1(1.9 \%)$ & 1.56 \\
\hline & RN \& RM & $54(93.1 \%)$ & $4(6.9 \%)$ & $(0.211)$ \\
\hline \multirow{2}{*}{ Infection } & University Degree (UG \& PG) & $50(96.2 \%)$ & $2(3.8 \%)$ & 0.50 \\
\hline & $\mathrm{RN} \& \mathrm{RM}$ & $54(93.1 \%)$ & $4(6.9 \%)$ & $(0.482)$ \\
\hline \multirow{2}{*}{ Irradiation } & University Degree (UG \& PG) & $25(48.1 \%)$ & $27(51.9 \%)$ & 0.32 \\
\hline & RN \& RM & $31(53.4 \%)$ & $27(46.6 \%)$ & $(0.574)$ \\
\hline \multirow{2}{*}{$\begin{array}{l}\text { Occupational and environmental } \\
\text { hazards }\end{array}$} & University Degree (UG \& PG) & $43(82.7 \%)$ & $9(17.3 \%)$ & 1.13 \\
\hline & $\mathrm{RN} \& \mathrm{RM}$ & $52(89.7 \%)$ & $6(10.3 \%)$ & $(0.288)$ \\
\hline \multirow{2}{*}{ Travel } & University Degree (UG \& PG) & $28(53.8 \%)$ & $24(46.2 \%)$ & 0.47 \\
\hline & RN \& RM & $35(60.3 \%)$ & $23(39.7 \%)$ & $(0.492)$ \\
\hline
\end{tabular}




\begin{tabular}{|c|c|c|c|c|}
\hline & & Yes & No & $\chi^{2}$ (p-value) \\
\hline \multirow{2}{*}{ Follow-up } & University Degree (UG \& PG) & $48(92.3 \%)$ & $4(7.7 \%)$ & 0.23 \\
\hline & RN \& RM & $52(89.7 \%)$ & $6(10.3 \%)$ & $(0.629)$ \\
\hline \multirow{2}{*}{ Minor discomforts } & University Degree (UG \& PG) & $45(86.5 \%)$ & $7(13.5 \%)$ & 1.48 \\
\hline & $\mathrm{RN} \& \mathrm{RM}$ & $45(77.6 \%)$ & $13(22.4 \%)$ & $(0.224)$ \\
\hline \multirow{2}{*}{$\begin{array}{l}\text { Birth preparedness and } \\
\text { complication readiness }\end{array}$} & University Degree (UG \& PG) & $46(88.5 \%)$ & $6(11.5 \%)$ & 0.13 \\
\hline & RN \& RM & $50(86.2 \%)$ & $8(13.8 \%)$ & $(0.723)$ \\
\hline \multirow{2}{*}{ Danger signs during pregnancy } & University Degree (UG \& PG) & $48(92.3 \%)$ & $4(7.7 \%)$ & 0.03 \\
\hline & RN \& RM & $53(91.4 \%)$ & $5(8.6 \%)$ & $(0.859)$ \\
\hline \multirow{2}{*}{ Danger signs during labour } & University Degree (UG \& PG) & $47(90.4 \%)$ & $5(9.6 \%)$ & 0.02 \\
\hline & $\mathrm{RN} \& \mathrm{RM}$ & $52(89.7 \%)$ & $6(10.3 \%)$ & $(0.899)$ \\
\hline \multirow{2}{*}{$\begin{array}{l}\text { Danger signs during postpartum } \\
\text { period }\end{array}$} & University Degree (UG \& PG) & $48(92.3 \%)$ & $4(7.7 \%)$ & 0.23 \\
\hline & RN \& RM & $52(89.7 \%)$ & $6(10.3 \%)$ & $(0.629)$ \\
\hline \multirow{2}{*}{ Immunization } & University Degree (UG \& PG) & $51(98.1 \%)$ & $1(1.9 \%)$ & 0.01 \\
\hline & $\mathrm{RN} \& \mathrm{RM}$ & $57(98.3 \%)$ & $1(1.7 \%)$ & $(0.938)$ \\
\hline \multirow{2}{*}{ Breastfeeding } & University Degree (UG \& PG) & $52(100 \%)$ & 0 & 1.83 \\
\hline & RN \& RM & $56(96.6 \%)$ & $2(3.4 \%)$ & $(0.177)$ \\
\hline \multirow{2}{*}{ Family planning } & University Degree (UG \& PG) & $50(96.2 \%)$ & $2(3.8 \%)$ & 1.05 \\
\hline & $\mathrm{RN} \& \mathrm{RM}$ & $53(91.4 \%)$ & $5(8.6 \%)$ & $(0.306)$ \\
\hline \multirow{2}{*}{ Umbilical cord care } & University Degree (UG \& PG) & $49(94.2 \%)$ & $3(5.8 \%)$ & 0.33 \\
\hline & RN \& RM & $53(91.4 \%)$ & $5(8.6 \%)$ & $(0.565)$ \\
\hline \multirow{2}{*}{ Essential newborn care } & University Degree (UG \& PG) & $50(96.2 \%)$ & $2(3.8 \%)$ & 1.72 \\
\hline & RN \& RM & $52(89.7 \%)$ & $6(10.3 \%)$ & $(0.190)$ \\
\hline
\end{tabular}

Fi- indicates p-value of the Fishers Exact test.

\section{F. Association between Purpose of Antenatal Education and Topic Taught during Health Education}

To check for association between purpose of health education and topic taught by the educators, it was revealed that none of topics taught was significantly associated with educating the clients to serve as a learning forum for the clients and educating the clients to showcase themselves as health educators.

In addition, a statistically significant association was found between educating the clients on daily activities and educating them for purpose of clinic routine $(\mathrm{p}=0.012)$, as p-value was below $5 \%$. Noteworthy is that $93 \%$ of those who engaged in the processes as a statutory clinic routine educated the clients on what to do on their daily activities, conversely, not more than $75 \%$ of those who did not educate the clients for purpose of clinic routine actually educated them in areas of recommended daily activities. A statistically significant association exists between teaching for the purpose of clinic routine and teaching on areas regarding occupational and environmental hazards $(\mathrm{p}=0.008)$, with $\mathrm{p}$ value below $5 \%$. It was revealing that almost $92 \%$ of those who educated on clinic routine taught about occupational and environmental hazards, while $71 \%$ of those who taught not because of clinic routine covered areas of occupational and environmental hazards.

A statistically significant association exists between teaching to keep the clients busy and educating them about irradiation $(\mathrm{p}=0.029)$. Thus, further revealing that almost three-quarter $(74 \%)$ of the educators who kept client busy remarked about irradiation, while not more than $46 \%$ of those who taught but not in attempt to keep the clients busy educated the clients about irradiation.
TABLE VI: ANTENATAL EDUCATION TOPICS TAUGHT BY NURSES FOR THE PURPOSE OF CLINIC ROUTINE

\begin{tabular}{|c|c|c|c|c|}
\hline & & Yes & No & $\begin{array}{c}\chi^{2} \\
\text { (p-value) }\end{array}$ \\
\hline \multirow{2}{*}{$\begin{array}{l}\text { Daily } \\
\text { activities }\end{array}$} & A clinic routine & $76(92.7 \%)$ & $6(7.3 \%)$ & \multirow{2}{*}{$\begin{array}{c}6.26 \\
(0.012)\end{array}$} \\
\hline & $\begin{array}{l}\text { Not a clinic } \\
\text { routine }\end{array}$ & $21(75 \%)$ & $7(25 \%)$ & \\
\hline \multirow{2}{*}{$\begin{array}{l}\text { Occupational } \\
\text { and } \\
\text { environmental } \\
\text { hazards }\end{array}$} & A clinic routine & $75(91.5 \%)$ & $7(8.5 \%)$ & \multirow[b]{2}{*}{$\begin{array}{c}7.11 \\
(0.008)\end{array}$} \\
\hline & $\begin{array}{l}\text { Not a clinic } \\
\text { routine }\end{array}$ & $20(71.4 \%)$ & $8(28.6 \%)$ & \\
\hline
\end{tabular}

TABLE VII: ANTENATAL EDUCATION TOPIC TAUGHT BY NURSES FOR THE PURPOSE OF KEEPING CLIENT BUSY

\begin{tabular}{ccccc}
\hline & Yes & No & $\begin{array}{c}\chi^{2} \\
\text { (p-value) }\end{array}$ \\
\hline \multirow{2}{*}{ Irradiation } & $\begin{array}{c}\text { To keep busy } \\
\text { Not to keep } \\
\text { busy }\end{array}$ & $14(73.7 \%)$ & $5(26.3 \%)$ & 4.77 \\
\hline
\end{tabular}

\section{G. Association between Cadre of Nurses and Identified Purpose of Antenatal Education}

Test of association carried out between cadre of nurses and purpose for teaching the health education topics showed that there is no statistically significant association between cadre of the participants and each of participation in educating their clients as a clinic routine $(p=0.285)$, educating the clients to keep them busy $(\mathrm{p}=0.542)$, and educating the clients to showcase as health educator $(\mathrm{p}=0.611)$.

A statistically significant association exists between cadre of the nurses/midwives and educating the clients to create a learning forum $(\mathrm{p}=0.035)$. It was notable from the results that all the nurses engaged in educating their clients to create a learning forum except the SNOs and PNOs; $11 \%$ and about $17 \%$ of the SNOs and PNOs indicated they do not educate their clients purpose of having a learning forum. 
TABLE VIII: ASSOCIATION BETWEEN CADRE OF NURSES AND IDENTIFIED PURPOSE OF ANTENATAL EDUCATION

\begin{tabular}{|c|c|c|c|c|c|c|c|c|c|}
\hline & & NO I & NO II & SNO & PNO & $\mathrm{ACNO}$ & $\mathrm{CNO}$ & $\begin{array}{l}\text { AND/ } \\
\text { DDN }\end{array}$ & $\begin{array}{c}\chi^{2} \\
\text { (p-value) }\end{array}$ \\
\hline \multirow{2}{*}{$\begin{array}{l}\text { For clinic } \\
\text { routine }\end{array}$} & Yes & $\begin{array}{c}17 \\
(77.3 \%)\end{array}$ & $\begin{array}{c}28 \\
(80 \%)\end{array}$ & $\begin{array}{c}6 \\
(66.7 \%)\end{array}$ & $\begin{array}{c}6 \\
(100 \%)\end{array}$ & $\begin{array}{c}4 \\
(80 \%)\end{array}$ & $\begin{array}{c}15 \\
(57.7 \%)\end{array}$ & $\begin{array}{c}6 \\
(85.7 \%)\end{array}$ & \multirow{2}{*}{$\begin{array}{c}7.41 \\
(0.285)\end{array}$} \\
\hline & No & $\begin{array}{c}5 \\
(22.7 \%)\end{array}$ & $\begin{array}{c}7 \\
(20 \%)\end{array}$ & $\begin{array}{c}3 \\
(33.3 \%)\end{array}$ & 0 & $\begin{array}{c}1 \\
(20 \%)\end{array}$ & $\begin{array}{c}11 \\
(42.3 \%)\end{array}$ & $\begin{array}{c}1 \\
(14.3 \%)\end{array}$ & \\
\hline \multirow{2}{*}{$\begin{array}{l}\text { Learning forum } \\
\text { for clients }\end{array}$} & Yes & $\begin{array}{c}22 \\
(100 \%)\end{array}$ & $\begin{array}{c}35 \\
(100 \%)\end{array}$ & $\begin{array}{c}8 \\
(88.9 \%)\end{array}$ & $\begin{array}{c}5 \\
(83.3 \%)\end{array}$ & $\begin{array}{c}5 \\
(100 \%)\end{array}$ & $\begin{array}{c}26 \\
(100 \%)\end{array}$ & $\begin{array}{c}7 \\
(100 \%)\end{array}$ & \multirow{2}{*}{$\begin{array}{c}13.52 \\
(0.035)\end{array}$} \\
\hline & No & 0 & 0 & $\begin{array}{c}1 \\
(11.1 \%)\end{array}$ & $\begin{array}{c}1 \\
(16.7 \%)\end{array}$ & 0 & 0 & 0 & \\
\hline \multirow{2}{*}{$\begin{array}{l}\text { To keep clients } \\
\text { busy }\end{array}$} & Yes & $\begin{array}{c}4 \\
(18.2 \%)\end{array}$ & $\begin{array}{c}6 \\
(17.1 \%)\end{array}$ & $\begin{array}{c}2 \\
(22.2 \%)\end{array}$ & $\begin{array}{c}1 \\
(16.7 \%)\end{array}$ & 0 & $\begin{array}{c}3 \\
(11.5 \%)\end{array}$ & $\begin{array}{c}3 \\
(42.9 \%)\end{array}$ & \multirow{2}{*}{$\begin{array}{c}5.02 \\
(0.542)\end{array}$} \\
\hline & No & $\begin{array}{c}18 \\
(81.8 \%)\end{array}$ & $\begin{array}{c}29 \\
(82.9 \%)\end{array}$ & $\begin{array}{c}7 \\
(77.8 \%)\end{array}$ & $\begin{array}{c}5 \\
(83.3 \%)\end{array}$ & $\begin{array}{c}5 \\
(100 \%)\end{array}$ & $\begin{array}{c}23 \\
(88.5 \%)\end{array}$ & $\begin{array}{c}4 \\
(57.1 \%)\end{array}$ & \\
\hline \multirow{2}{*}{$\begin{array}{l}\text { To showcase as } \\
\text { health educator }\end{array}$} & Yes & $\begin{array}{c}11 \\
(50 \%)\end{array}$ & $\begin{array}{c}16 \\
(45.7 \%)\end{array}$ & $\begin{array}{c}7 \\
(77.8 \%)\end{array}$ & $\begin{array}{c}3 \\
(50 \%)\end{array}$ & $\begin{array}{c}2 \\
(40 \%)\end{array}$ & $\begin{array}{c}13 \\
(50 \%)\end{array}$ & $\begin{array}{c}2 \\
(28.6 \%)\end{array}$ & \multirow{2}{*}{$\begin{array}{c}4.49 \\
(0.611)\end{array}$} \\
\hline & No & $\begin{array}{c}11 \\
(50 \%) \\
\end{array}$ & $\begin{array}{c}19 \\
(54.3 \%) \\
\end{array}$ & $\begin{array}{c}2 \\
(22.2 \%) \\
\end{array}$ & $\begin{array}{c}3 \\
(50 \%) \\
\end{array}$ & $\begin{array}{c}3 \\
(60 \%) \\
\end{array}$ & $\begin{array}{c}13 \\
(50 \%) \\
\end{array}$ & $\begin{array}{c}5 \\
(71.4 \%) \\
\end{array}$ & \\
\hline
\end{tabular}

\section{H. Proportion of Expected Antenatal Education Topics Observed by Nurses \& Midwives}

The overall topics taught by the nurses and midwives was expressed in terms of percentage. Out of the 28 out-listed topics on the instrument; the least percentage topic taught was $39 \%$ of 28 (11 topics) while some nurses and midwives were observed to have been teaching all the 28 listed health education topics $(100 \%)$. On the average, the nurses and midwives reported teaching up to $89 \%$ of the expected topics (25 topics).

The test of difference in the proportion of expected topics taught by the nurses and midwives, across their level of education was not statistically significantly different, as pvalue was greater than $5 \%(p=0.155)$. Noteworthy is that an average participant who had a RN + RM or RN + any other post-basic taught up to $93 \%$ of expected topics; those with a university first degree or postgraduate degree averaged $89 \%$ of the expected topics; while those with RN qualification averaged $75 \%$ of the expected topics.

A test of difference in the proportion of expected topics taught by the nurses and midwives, dispersed by the cadre of the nurses exposed that no statistically significant difference exists across the cadre categories, given p-value of 0.054 , which is higher than $5 \%$. Average, participants who were ADN taught all the topics as expected (100\%); ACNOs and CNOs averagely taught $93 \%$ of the expected topics; the PNOs taught $95 \%$ of the expected topics; NO I and NO II taught about $86 \%$ of the topics expected of them; and lastly, SNOs observed about $82 \%$ of the expected topics.

TABLE IX: PROPORTION OF ANTENATAL EDUCATION TOPICS TAUght By

\begin{tabular}{cccccc}
\multicolumn{5}{c}{ NuRSES } \\
\hline & Min. & Max. & Median & $\begin{array}{c}\text { First } \\
\text { quartile }\end{array}$ & $\begin{array}{c}\text { Third } \\
\text { quartile }\end{array}$ \\
\hline $\begin{array}{c}\% \text { of } \\
\begin{array}{c}\text { recommended } \\
\text { health education } \\
\text { topics taught }\end{array}\end{array}$ & 39.3 & 100 & 89.3 & 82.1 & 96.4 \\
\hline
\end{tabular}

TABLE X: TEST OF DifFERENCE IN PROPORTION OF TOPICS TAUGHT By LEVEL OF EDUCATION OF THE NURSES

\begin{tabular}{ccccc}
$\begin{array}{c}\text { \% of recommended health } \\
\text { education topics taught by level } \\
\text { of education of the nurses }\end{array}$ & Min. & Max. & Median & p-value \\
\hline Postgraduate & 82.1 & 96.4 & 89.3 & \\
University first degree & 46.4 & 100 & 89.3 & \\
RN & 46.4 & 100 & 75 & 0.155 \\
RN + RM & 50 & 100 & 92.9 & \\
RN + any other post-basic & 39.3 & 100 & 92.9 & \\
\hline
\end{tabular}

TABLE XI: Test of DifFERENCE IN PROPORTION OF TOPICS TAught by DIFFERENT CADRES OF NURSES

\begin{tabular}{ccccc}
\hline $\begin{array}{l}\text { \% of recommended health } \\
\text { education topics taught by } \\
\text { cadre of the nurses }\end{array}$ & Min. & Max. & Median & p-value \\
\hline NO I & 39.3 & 100 & 85.7 & \\
NO II & 78.6 & 100 & 85.7 & \\
SNO & 78.6 & 100 & 82.1 & \\
PNO & 67.9 & 100 & 94.6 & 0.054 \\
ACNO & 89.3 & 100 & 92.9 & \\
CNO & 67.9 & 100 & 92.9 & \\
ADN & 89.3 & 100 & 100 & \\
\hline
\end{tabular}

\section{DISCUSSION}

This study assessed the contents and mode of delivery of antenatal education from the perspective of nurses and midwives in Oyo state, Nigeria. The mean age of the participants was 40 years, they were predominantly Yoruba by tribe, this is not surprising as Oyo state mainly inhabited by the Yoruba ethnic group. Most of the nurses and midwives in the study were University graduates which is a welcomed development in nursing in Nigeria as this indicates a positive change from the perceived low educational status of nurses and midwives.

Considering the content of ante-natal education often delivered by the participants, all the important topics were reportedly covered by the participants while the five commonest health education topics provided were hygiene, diet, immunization, birth preparedness and breastfeeding Although, some of the participants indicated that they did not provide health education to their clients on danger signs during pregnancy, labour and postpartum period this is significant as pregnant women who lack information on how to recognize danger signs during these periods may not be able to take appropriate healthcare seeking action when they experience such signs. It is therefore important for nurses and midwives to provide adequate information on danger signs during perinatal period for all pregnant women. Another topic of obstetric importance that about half of nurses and midwives in the study did not educate their clients about is irradiation. Many foetal risks have been found to be associated with the exposure to irradiation during pregnancy [27] Nurses and midwives should ensure that this aspect is always included in their health education topics.

In this study, the most common methods used by almost all the participants during antenatal education was teaching methods. 
Regarding the purpose of antenatal education provided by the nurses and midwives, almost all of them indicated they provided health educational to serve as a learning forum for their clients, although about three-quarter reported they provided health education just as a statutory clinic routine; however, almost half of the participants claimed to provide health education to the clients to showcase themselves as health educators while few of the participants indicated that they engaged in educating their clients just to keep the clients busy while waiting for doctor's consultation. It is worthy of note that nurses and midwives as first-line health educators in health care settings should consider the purpose of providing health education as a means of empowering patients/clients to improve their health status.

Health education is any combination of learning experiences designed to help individuals and communities improve their health, by increasing their knowledge or influencing their attitudes.

\section{ACKNOWLEDGMENT}

We would like to thank all Nurses and midwives who participated in this study

\section{REFERENCE}

[1] M. Boah, B. Abraham, A. B. Mahama, A., Emmanuel and E.A Ayamga (2018). They receive antenatal care in health facilities, yet do not deliver there: predictors of health facility delivery by women in rural Ghana. BMC Pregnancy and Childbirth, 18(125) (2018).

[2] World Health Organization (WHO), UNICEF, UNFPA, World Bank Group, and the United Nations Population Division. Trends in Maternal Mortality: 2000 to 2017. Geneva, World Health Organization, 2019.

[3] World Health Organization. Trends in Maternal Mortality: 1990 to 2015: Estimates Developed by WHO, UNICEF, UNFPA, World Bank Group and the United Nations Population Division. Geneva https://reliefweb.int/report/world/trends-maternal-mortality-19902015-estimates-who-unicef-unfpa-world-bank-group- World Health Organization (2017).

[4] United Nations. Sustainable Development Goal Indicators (E/CN.3/2019/2).

[5] R. Sageer, E. Kongnyuy, W.O. Adebimpe, O. Omosehin, E.A. Ogunsola, and B. Sanni (2019). Causes and contributory factors of maternal mortality: evidence from maternal and perinatal death surveillance and response in Ogun state, Southwest Nigeria. BMC Pregnancy and Childbirth. 19(63) (2019).

[6] C.E.M. Okoror, and E. Sidze (2019). Prenatal Care Education: An Assessment of Sources and Preferences Regarding Birth Preparedness and Complication Readiness Information among Women in Edo State Nigeria. American Journal of Medicine and Medical Sciences, 9(7): 242-248 DOI: 10.5923/j.ajmms.20190907.04.

[7] M.M.A., Almalik and S.M., Mosleh, (2017). Pregnant women: What do they need to know during pregnancy? A descriptive study. Women and birth: journal of the Australian College of Midwives, 30(2): 10010.

[8] Y. Shimpuku, E. Frida, F.E. Madeni, S. Horiuchi, K. Kubota and S.C. Leshabari. (2018). Evaluation of a family-oriented antenatal group educational program in rural Tanzania: a pre-test/post-test study. Reproductive Health. 15:117. https://doi.org/10.1186/s12978-0180562-z.

[9] A. Salama, and F. Aly. (2019). Effect of Antenatal Instructional Package on Pregnant Women' Knowledge, Attitude and Practices. American Journal of Nursing Research, 7(4)519-533 DOI: 10.12691/ajnr-7-4-14.

[10] U.N. Jibril (2017). Awareness and Use of Antenatal Care Services among Women in Edu LGA, Kwara State, Nigeria. J Comm Pub Health Nurs, 3:184. doi:10.4172/2471-9846.1000184.
[11] Nidhi, (2018). Effectiveness of self-instructional module on knowledge and attitude regarding antenatal care among primigravida mothers in selected government hospital, Dehradun, Uttarakhand. Int J Med Sci Public Health; 7(8):651-654.

[12] A.A. Abdel Hafez, E.M Makhlou, and O. Mohammed (2018). Effect of antenatal educational guidelines on mother's knowledge. IOSR Journal of Nursing and Health Science .7(2) 21-26.DOI: 10.9790/1959-0702062126.

[13] J. Sharma, M. O'Connor, and R. Rima Jolivet (2018). Group antenatal care models in low- and middle-income countries: a systematic evidence synthesis. Reprod Health 15(38). https://doi.org/10.1186/s12978-018-0476-9.

[14] U.N. Jibril, N.G. Saleh, O. Badaki, E.E. Anyebe, A. Umar and A. Kamal, A. (2018). Health Education Intervention on Knowledge and Accessibility of Pregnant Women to Antenatal Care Services in Edu, Kwara State, Nigeria. IJWHR; 6: 154-160. DOI 10.15296/ijwhr.2018.26.

[15] C. O'Sullivan, R. O'Connell and D. Devane, (2014). A descriptive survey of the educational preparation and practices of antenatal educators in Ireland. The Journal of Perinatal Education, 23(1):33-40 DOI: 10.1891/1058-1243.23.1.33 PMID: 24453466 PMCID: PMC3894593.

[16] S.S Piro, and H.M. Ahmed (2020). Impacts of antenatal nursing interventions on mothers' breastfeeding self-efficacy: an experimental study. BMC Pregnancy and Childbirth; 20(19).

[17] J. Nankumbi, T.D. Ngabirano, and G. Nalwadda (2018). Maternal Nutrition Education Provided by Midwives: A Qualitative Study in an Antenatal Clinic, Uganda. Journal of Nutrition and Metabolism. https://doi.org/10.1155/2018/3987396.

[18] K. Bookari, H. Yeatman, and M. Williamson (2017). Informing Nutrition Care in the Antenatal Period: Pregnant Women's Experiences and Need for Support. Bio Med Research International Article. https://doi.org/10.1155/2017/4856527.

[19] M.C Chikalipo, E.M Chirwa, and A.S. Muula. (2018). Exploring antenatal education content for couples in Blantyre, Malawi. BMC Pregnancy and Childbirth, 18:497 https://doi.org/10.1186/s12884018-2137-y

[20] M. Sharifi, L. Amiri-Farahani and S. Haghani. (2020). Information Needs during Pregnancy and Its Associated Factors in Afghan Pregnant Migrant Women in Iran. Journal of Primary Care \& Community Health.11 https://doi.org/10.1177/2150132720905949.

[21] C.U. Nwankwo, J.O. Okafor, M.C. Makachi, J.E. Anieche, E.N. Chiejina, and O.L Egboka (2016). Effect of maternal health education on the health knowledge of Pregnant Mothers Attending Ante-Natal Clinics in Anambra State, Nigeria. IOSR Journal of Nursing and Health Science (IOSR-JNHS), 5, (1) DOI: 10.9790/1959-05175663.

[22] H. Aji, F. Awg-Manan, R. Abdullah, R. Yura-Rahayu Kisut, H. Abdul Rahman, and K. Mumin (2018). Antenatal education for pregnant women attending maternal and child health clinics in Brunei Darussalam. Women and Birth. (32).DO 10.1016/j.wombi.2018.11.005.

[23] I.S. Dasuki, and E.D. Zamani (2019). Assessing mobile phone use by pregnant women in Nigeria: A capability perspective. The Electronic Journal of Information Systems in Developing Countries. https://doi.org/10.1002/isd2.12092.

[24] T. Otaiby, H. Jradi, and A. Bawazir (2013). Antenatal Education: An Assessment of Pregnant Women Knowledge and Preferences in Saudi Arabia. J Women's Health Care, 2:4 DOI: 10.4172/21670420.1000139.

[25] H.J. Kim and H.S. Kang (2019). Mobile Web-based Education: Engagement and Satisfaction with HiChart among Pregnant Women. Child Health Nurs Res; 25(3): 303-311. DOI: https://doi.org/10.4094/chnr.2019.25.3.303.

[26] C. Jones, F., Wadephul, and J. Jomeen J (2019). Research Maternal and paternal expectations of antenatal education across the transition to parenthood. British Journal of Midwifery. Vol. 27 (4) https://doi.org/10.12968/bjom.2019.27.4.235.

[27] R.L Brent (2009). Saving lives and changing family histories: appropriate counseling of pregnant women and men and women of reproductive age, concerning the risk of diagnostic radiation exposures during and before pregnancy. American Journal of Obstetrics \& Gynaecology 200(1):4-24. doi: 10.1016/j.ajog.2008.06.032.

[28] A. Malata, and E. Chirwa, (2011). Childbirth information needs for first time Malawian mothers who attended antenatal clinics. Malawi Medical Journal: The Journal of Medical Association of Malawi, 23(2):43-47, DOI: 10.4314/mmj.v23i2.70747 PMID: 23074811 PMCID: PMC3627698. 